\title{
CONHECIMENTO, PLANIFICAÇÃO E SUSTENTABILIDADE
}

\author{
Maíra Baumgarten
}

\begin{abstract}
Resumo: Este artigo aborda as relações entre conhecimento científico, planificação e sustentabilidade. São analisados os paradigmas da ciência e da planificação modernas e seu envolvimento no processo de valorização do capital, gerando o que vem sendo chamado de sociedade do conhecimento. A seguir essa análise é tomada como ponto de partida para uma breve reflexão sobre a inserção periférica do Brasil na sociedade do conhecimento e as potencialidades de uma planificação emancipatória como instrumento para a busca de sustentabilidade econômica e social.

Palavras-chave: ciência; planificação; sustentabilidade.
\end{abstract}

Abstract: This article addresses the relationship between scientific knowledge, planning and sustainability. The paradigms of modern science and planning are analyzed, as well as their role in the process of capital creation, generating what is coming to be known as the society of knowledge. This analysis serves as the starting point for a two-fold reflection: first, on the peripheral insertion of Brazil in the society of knowledge, and second, on the how independent planning can be instrumental in attaining economic and social sustainability. Key words: science; planning; sustainability.

A o traçar um esboço de momentos significativos da relação entre conhecimento científico e planejamento no século $\mathrm{XX}$, esses surgem como elementos decisivos no processo de construção da sociedade capitalista. Por um lado, a análise dos paradigmas modernos de ciência e de planificação desvenda seus vínculos com as formas de produção e de distribuição de bens fundadas no produtivismo e na racionalidade instrumental.

Por outro lado, um olhar lançado sobre as últimas décadas do século descortina múltiplas transformações que remodelam a base material da sociedade com base em estratégias de acumulação que se apóiam em processos de geração e de difusão de novos conhecimentos. A expansão das esferas financeira e técnico-produtiva e a aceleração de processos de deslocalização e de segmentação econômica e social criam grandes tensões que originam a estruturação de novas demandas de políticas e de instrumentos de regulação.

A noção de sustentabilidade desenvolve-se com múltipla e longa crise que se instala no último terço do século $\mathrm{XX}$, durante o processo contraditório, desigual e heterogêneo de formação da sociedade global.

$\mathrm{O}$ sistema desigual de trocas que atravessa o planeta e gera exclusão social; a crescente incapacidade dos Esta- dos nacionais em controlar os efeitos perversos da tecnociência sobre o ambiente, bem como os riscos para a humanidade, associados às formas predatórias de utilização do trabalho e da natureza são alguns dos elementos que sinalizam para a urgência em desenvolver estratégias sócio-político-ambientais sustentáveis e em incorporar princípios éticos ao desenvolvimento econômico e técnico-científico.

O cenário de abertura do século recoloca grandes desafios para as ciências sociais: desenvolver conceitos e teorias que sirvam como instrumentos para compreender e intervir sobre processos que têm fortes repercussões sobre a vida cotidiana e cuja evolução não se encontra predeterminada. Refletir sobre as condições de sustentabilidade social, econômica e natural no século XXI requer o exercício da reflexividade, buscando novas formas de pensar, capazes de identificar, nas bifurcações e desvãos do futuro, as alternativas para a construção de relações solidárias entre seres humanos e de maior harmonia entre eles e seu ambiente natural.

A seguir são identificados processos, concepções e atitudes que têm norteado a ciência, sua vinculação com os movimentos de planificação no século XX e seu envol- 
vimento no processo de valorização do capital, gerando a sociedade do conhecimento.

\section{CONHECIMENTO E PLANIFICAÇÃO MODERNOS: GÊNESE, PARADIGMAS E CRISE}

\section{Sociedade versus Natureza: o paradigma da ciência}

As carências humanas, seu desenvolvimento e as trocas que originam entre homem e meio natural e social formam o eixo em torno do qual gira o processo de conhecimento humano. Como ser vivente o homem integra a natureza e desfruta com ela uma relação de parte com o todo. Ser humano é fazer parte da natureza. Assim, o homem, como ser vivo consciente de si e de seu entorno, como ser social exerce sobre a natureza uma ação deliberada que visa satisfazer às suas necessidades. Nessa ação (o ser humano) emprega suas qualidades naturais (força vital) opondo-se à matéria da natureza, modificando-a.

Nessa perspectiva, as relações entre natureza, sociedade, ciência e técnica são permanentemente construídas. No desenvolvimento histórico - processo geral de naturalização/humanização (hibridação) - forças simultaneamente naturais e sociais conformam o conhecimento do humano, que é, ao mesmo tempo, sujeito e objeto na busca pela compreensão da natureza e da sociedade as quais integra. A procura por conhecimento é parte constituinte da estratégia de sobrevivência da espécie humana. No entanto, esse conhecer será sempre condicionado pela situação concreta de cada sociedade, por seu estado da arte, por sua prática de vida, sua cultura, suas técnicas, suas ideologias. Conhecimento e técnica contêm uma estrutura de valores orientada conforme a classe, a cultura, o sexo, valores esses oriundos da própria experiência humana que os criou.

A história da ciência encontra-se profundamente imbricada com a perspectiva humana sobre a natureza e com as formas assumidas pelas relações entre os homens e deles com a natureza na produção de sua vida.

Uma nova relação com a natureza acompanha o declínio das sociedades tradicionais predominantemente agrárias e a estruturação de um modo de produção social cuja base é constituída pelo comércio e pela indústria. A natureza deixa de ser reconhecida como uma potência por si, como ordem de todas as coisas, passando a ser percebida como algo exterior ao humano, algo que deve (e pode) ser submetido e utilizado seja como objeto de consumo, ou como meio de produção.
O princípio de Vico (1988) no qual (...) só conhecemos as razões daquilo que podemos construir com as mãos ou com o intelecto (...) orienta a ciência baconiana ${ }^{1}$ que percebe a natureza como uma selva, um labirinto para o qual o método fornece o fio de Ariadne, necessário para o desvelamento de seus segredos e, com isso, a apropriação de suas virtualidades de poder. O critério de verdade que se impõe, então, é o da efetividade e eficiência. Conhecer como fazer é o que importa, estabelecendo-se identidade entre conhecer e construir ou reconstruir.

Desde a revolução industrial, os modos de apreensão e conhecimento dos fenômenos naturais e sociais que se estruturam conjuntamente com as novas formas materiais de produção da vida assumem uma perspectiva de futuro articulada à idéia de progresso visto, este, como processo dinâmico, contínuo e irreversível de mudança tecnológica. A premissa aqui envolvida é a de uma base técnica em mutação evolutiva. Toda a perspectiva de futuro nos séculos XIX e XX tem por base os avanços científicos e tecnológicos (Marinho e Quirino, 1995).

A racionalidade instrumental que orienta o chamado paradigma da ciência moderna articula-se à racionalidade utilitária característica da cultura industrial ocidental. Em linhas gerais, a ciência moderna tem sido definida como instrumento na procura pelo conhecimento, visando à dominação e ao controle da natureza e, eventualmente, à planificação da sociedade. O paradigma da ciência moderna estabeleceu uma cisão e um distanciamento radicais com seu objeto - a natureza - visto como exterior, inanimado e passivo.

Esse modelo de racionalidade científica - cognição regida por causalidade e determinismo, aspirando atingir verdades paradigmáticas e consensuais - construiu-se em oposição a outros modelos de conhecimento concorrentes e consolidou-se pela identidade com as formas materiais de produção características da sociedade capitalista sendo, ele próprio, instrumento de legitimação e força produtiva fundamental dessa sociedade (Habermas, 1975; Santos, 2000).

A constituição da natureza como objeto (separado e estranho ao sujeito) está na base da revolução tecnológica que se respalda em uma razão instrumental, cujo objetivo é a manipulação dos fenômenos naturais. A tecnologia, resultado desse processo, aos poucos se autonomiza da sociedade como esfera autodiretiva. A ambigüidade tecnológica contemporânea em que técnica e ciência surgem, ao mesmo tempo, como perigo e como elemento de salvação da humanidade, decorre, fundamentalmente, des- 
sas características históricas de seu desenvolvimento (Moraes, 1997).

A crescente inter-relação, no século XX, entre ciência, tecnologia e produção de bens e serviços, transforma o modo de produção do conhecimento que passa a ser objeto de planejamento e de políticas governamentais. Na era da big science, atividades de pesquisa cada vez mais complexas e dispendiosas exigem sofisticados aparatos instrumentais e institucionais, ocupando lugar destacado no próprio centro do sistema produtivo.

De acordo com Santos (1989), na fase da industrialização da ciência, sua eficácia garante o apoio financeiro e um crescente processo de institucionalização. Não há mais distinção entre ciência e tecnologia: a tecnologia cientifica-se e o conhecimento científico converte-se em projeto tecnológico. Produção teórica e investimento científico passam a ser apoiados por uma complexa infra-estrutura de equipamentos tecnológicos, transformando-se, a ciência, em força produtiva de tecnologia e, ao mesmo tempo, em força produzida pela tecnologia, ambas envolvidas, a fundo, no processo de valorização do capital.

O século XX é, também, o marco histórico da planificação que, tal como a ciência, origina-se em necessidades e interesses humanos, articulando-se a determinadas práticas, atitudes e concepções de mundo. Em sua forma moderna, o planejamento é, de modo geral, orientado pela noção de recursos escassos, pela busca de racionalização desses recursos e pela vontade de alcançar maior eficiência nos campos da produção e da distribuição de bens. No item a seguir será delineado o paradigma da planificação moderna e analisadas as relações entre Estado, ciência e acumulação capitalista.

\section{Paradigma da Planificação: ${ }^{2}$ \\ Estado, ciência e acumulação capitalista}

A planificação moderna pode ser definida como atividade que visa fixar objetivos coerentes e prioridades para o desenvolvimento econômico e social, determinar os meios apropriados para atingir tais objetivos e colocá-los em prática (Bettelheim, 1968).

Suas raízes históricas encontram-se: nas necessidades práticas de organização das empresas capitalistas que, ao final do século XIX, passam a desenvolver planos corporativos; nas necessidades coletivas de organização da sociedade socialista no que se refere à racionalização da produção e do consumo; e nas necessidades da organi- zação capitalista em nível nacional (Arrighi, 1996; Bettelheim, 1968; Zamora, 1966).

A generalização das atividades de planejamento no século XX se relacionou, por um lado, à Revolução Russa e à necessidade de reconstruir o país. Com a vitória de Stalin, foi aprovado em 1928 o Primeiro Plano Qüinqüenal que priorizou a produção de bens de capital, de energia e a indústria pesada, mais à frente orientada para a produção armamentista (Hobsbawm, 1996). No mundo capitalista, por outro lado, o planejamento buscou encaminhar soluções para a economia e suas crises. O New deal nos Estados Unidos da década de 30 e o Plano Marshall no Pós-Guerra (1947) na Europa Ocidental são exemplos de planejamento de tipo indicativo, ao contrário da planificação na Alemanha Nazista e na Itália Fascista, que se caracterizam pelo caráter imperativo.

De acordo com Tavares dos Santos (2001) há similitude paradigmática entre os modelos de planejamento socialista e capitalista indicativo. Ambos partem da suposição de que é possível controlar o sistema econômico e guiá-lo para fins desejados. O autor destaca como componentes do paradigma da planificação moderna: o estatismo da planificação - intervencionismo direto ou indireto na produção - identificado tanto pelo dirigismo norte-americano quanto pelo totalitarismo nazista ou stalinista; a construção de um modelo com base em uma visão de planejamento da economia; e a noção de superioridade da grande produção agrícola/industrial como motor de crescimento econômico, cujo pressuposto é a possibilidade de gasto ilimitado de energia (Tavares dos Santos, 2001:168, 169).

Essas características do paradigma traduzem sua íntima associação à idéia de desenvolvimento econômico e progresso em que a natureza é transfigurada em recurso natural, o trabalho, em recurso humano, ambos bens econômicos que devem ser geridos como recursos escassos na busca da produtividade crescente, própria ao processo de acumulação capitalista.

No período que se seguiu à Segunda Guerra Mundial, o Estado passou a interferir, crescentemente e de forma direta, na economia e na sociedade como planejador, empresário e investidor. Ao mesmo tempo, um pequeno número de grandes empresas, que se expandiam internacionalmente (multinacionais) tendo a inovação tecnológica como base do desenvolvimento de suas atividades econômicas, estabeleceu sua hegemonia sobre outras empresas.

Nesse contexto, as possibilidades de aplicação prática da ciência e tecnologia levaram o Estado a subvencionar 
pesquisas e a planejar o desenvolvimento científico e tecnológico levando em conta o aprimoramento dos meios de produção e a formação do especialista, do cientista, do técnico.

A fase monopolista do capital trouxe à cena econômica e política um novo modo de acumulação e novas formas de intervenção e planificação, inaugurando-se uma era ímpar no que diz respeito ao bem-estar social. A política keynesiana - ênfase na demanda agregada, no combate ao desemprego e na integração da classe operária fornecia condições para o surgimento e institucionalização dos estados capitalistas democráticos na Europa do pósguerra. O planejamento ocupou um papel central na configuração e desenvolvimento dos Estados de Bem-Estar Social, garantidos pelo chamado círculo virtuoso do fordismo central (a contínua adaptação do consumo de massa aos ganhos de produtividade).

A manutenção de regimes de Welfare State ${ }^{3}$ foi resultado, também, do processo de luta pela construção de direitos civis, políticos, sociais. As formas de concretizar e de implementar essas políticas variaram segundo as situações históricas concretas de cada sociedade e as diferentes concepções do papel do Estado.

Ao final dos anos 60, após longo período de prosperidade, esse modelo entrou em crise. Limites técnicos e sociais afetaram duramente a lucratividade das empresas, impedindo o contínuo aumento da valorização do capital com base no aumento da produtividade. A partir de 1973 o mundo capitalista imergiu em longa recessão, combinando baixas taxas de crescimento com altas taxas de inflação. A crise global representou a crise do Estado de Bem-Estar e ruptura do paradigma da planificação moderna, seja pelas políticas neoliberais de ajuste econômico, e de proposição de um estado mínimo, seja pela própria internacionalização dos conglomerados econômicos (Tavares dos Santos, 2001:170).

\section{SOCIEDADE GLOBAL E TECNOCIÊNCIA: A LÓGICA DO LUCRO MÁXIMO}

As últimas décadas do século XX caracterizaram-se por mudanças significativas nas formas de produção e acumulação capitalista. A resposta à crise sistêmica dos anos 70 ocorreu basicamente em duas frentes: a expansão do sistema; e a produção de bens de tipo radicalmente novo (Jameson, 1999:187).

A primeira frente diz respeito à chamada globalização, que pode ser traduzida por financeirização acelerada e crescente da economia mundial. A globalização opera de modo desigual para os diferentes atores: o capital movese livremente em busca de espaços de valorização, pressionando pela abertura dos mercados nacionais e pela desregulamentação do trabalho. Os trabalhadores, entretanto, são limitados às fronteiras nacionais. A expansão das esferas financeira e técnico-produtiva faz-se acompanhar pela aceleração dos processos de deslocalização e segmentação econômica e social.

O Estado, por sua vez, tende a assumir nova forma e outros papéis. Sua intervenção dá-se com intuito de baixar os custos de produção (legislação trabalhista modificada), garantir a estabilidade da moeda (câmbio), a institucionalização dos ajustes macroeconômicos necessários à livre expansão do capital e impulsionar a revolução tecno-científica e gerencial, cujos objetivos indissociáveis são: mudar o perfil da composição do mundo do trabalho e aumentar sua produtividade (Vilas, 1999; Roio, 1999).

A segunda estratégia de resposta à crise - a produção de tipos radicalmente novos de bens - apóia-se no recurso a inovações e "revoluções" na tecnologia (Jameson, 1999:188). Uma maior intensidade na utilização de informação e de conhecimento nos processos de produção, de comercialização e consumo de bens e serviços, bem como na cooperação e competição entre agentes e na circulação e valorização do capital leva a novas práticas nesses processos. As tecnologias de informação e de comunicação têm sido vistas como centrais na nova dinâmica técnicoeconômica. Novos saberes e competências, aparatos e instrumentos tecnológicos, produzem tipos novos de bens, viabilizando a abertura de espaços de atuação e mercados, encolhendo o globo e reorganizando o capitalismo em uma escala diferente e ampliada (Lastres e Albagli, 1999).

Objeto de apropriação privada, a técnica incorpora a ciência, convertendo-se em tecnociência que se transmuta em mercadoria de alto valor, inserida, de modo progressivo, no cotidiano das sociedades, em sua estrutura de poder e em suas matrizes simbólicas e culturais (Albagli, 1999).

A financeirização da economia, o fortalecimento dos mercados, diante dos Estados, como instâncias reguladoras e a utilização intensiva de conhecimento e informação configuram nova forma de relação entre economia, Estado e sociedade. Alteram-se radicalmente as condições de existência de parcelas significativas de populações tanto nos centros capitalistas do Norte, quanto nos países periféricos do Sul. 
A ampliação e generalização do sistema desigual de trocas e as novas estratégias de acumulação geram, ao mesmo tempo e de forma complementar, riqueza ímpar e maior exclusão econômica e social. A pobreza dissemina-se na América do Sul, Ásia e África e surgem inúmeros bolsões de excluídos (migrantes, desempregados) nos países do Norte. Novos conflitos sociais emergem da desigualdade crescente, o capital expande-se e ultrapassa limites legais e morais buscando o lucro rápido e certo da indústria da guerra e das atividades ilícitas: narcotráfico, crime organizado.

Pode-se afirmar que se depara, atualmente, com uma globalização planetária do processo racional de "perseguição de lucro máximo" que integra a civilização capitalista (Carvalho, 2000). A racionalidade instrumental característica do capitalismo traz em si duas tendências: a) a do desencaixe entre sociedade, política e economia, em que a economia de mercado é um sistema auto-regulado, não encaixado na sociedade, escapando aos controles sociais, morais e políticos; e b) a quantificação crescente, ou seja, o predomínio do espírito de cálculo racional, com a monetarização das relações sociais (Löwy, 2000).

As novas tecnologias de informação e comunicação facilitam e agilizam o movimento mundial de capitais que circulam mais rápida e facilmente que as mercadorias. $\mathrm{O}$ mercado unificado de capitais funciona em tempo real e a tomada de decisões é instantânea. A crescente dificuldade dos Estados em controlar a massa de mercadorias e os capitais especulativos traduz-se em conflito de base entre planejamento nacional dos países e o planejamento internacional efetuado pelas empresas com interesses transnacionais.

A reforma do Estado com a exclusão da arena política dos interesses desafinados com a perseguição do lucro máximo e a concomitante privatização da esfera pública resultam em crescente e generalizada dissociação entre Estado e sociedade civil. A crise dos sistemas políticos e o incremento das desigualdades mediante mecanismos de seleção e fragmentação têm originado tendências de reagrupação das populações em torno de identidades primárias religiosas, étnicas, territoriais. O local/regional contrapõe-se ao global, que se reafirma pela mídia que, por sua vez, encurta as distâncias, transforma o tempo e (des)orienta comportamentos, impondo padrões de pensamento e de consumo.

A concepção de mundo hegemônica da sociedade contemporânea resulta do enfrentamento entre valores em um campo de conflitos no qual os critérios ligados à dignida- de humana e à preservação da natureza vêm sendo rejeitados, vistos como freios ao progresso, em razão de sua incompatibilidade com a busca do lucro máximo.

A crise da ciência - que se expressa tanto pelo questionamento de suas aplicações como pela crítica de seus pressupostos, objeto e métodos - encontra-se relacionada à percepção dos limites e, mesmo, dos riscos de um conhecimento gerado para a dominação, controle (da sociedade) e domesticação (da natureza).

Tecnociência e capital, intimamente relacionados, estão envolvidos: na definição de agendas de pesquisa valendo-se de interesses de criação de novos mercados; nas manipulações genéticas atuais que podem ocasionar dramáticas conseqüências para a biodiversidade; na apropriação privada de organismos vivos que pode resultar no controle do mercado mundial de exportações agrícolas e na criação de mecanismos e instrumentos que levam à destruição em guerras instantâneas, à degeneração da vida e à desestruturação social.

Por intermédio da tecnociência, o capital penetra nos corpos vivos em busca de novos espaços de exploração: transgênicos, técnicas de clonagem, produção de órgãos, máquinas inteligentes - pesquisas e criações que concretizam assustadoras possibilidades mostradas na literatura ficcional, ${ }^{4}$ despertando debates sobre as potencialidades perversas de uma ciência que perdeu a humanidade no (super)mercado.

Ao lado das realidades/potencialidades sombrias do conhecimento atual há, não obstante, extraordinários avanços para solução de carências humanas em áreas vitais como a produção de alimentos, a medicina, a comunicação. Poderosos instrumentos de elevação da qualidade de vida são criados, mas o acesso a esses bens é restrito. $\mathrm{O}$ caráter ambivalente do conhecimento técnico-científico expresso na tensão entre suas virtualidades progressivas e regressivas (Morin, 1999) remete à sua articulação aos interesses presentes na sociedade.

Como empreendimento coletivo, as ciências, as técnicas e suas instituições, seguem a racionalidade que circula no conjunto das relações humanas. Os fatos científicos e os objetos técnicos são, em verdade, concretização de redes de relações que ligam seres humanos e coisas (naturais ou artificiais) e, como tal, também são humanos e incluem interesses políticos, econômicos e valores sociais e morais (Araújo, 1998:13).

A tecnociência - pressuposto e resultado da estruturação social e econômica contemporânea - deve ser objeto de permanente discussão e avaliação tanto por sua influên- 
cia na vida cotidiana e nas estratégias em escala mundial, quanto pelos possíveis impactos de suas aplicações na vida das gerações futuras.

Uma crítica conseqüente das atuais relações entre seres humanos, seu ambiente (natural e artificial) e o saber que se constrói nessas relações e que, reciprocamente, as informa passa pela crítica às formas fetichizadas de produção da vida pelas quais, natureza e sociedade transmutaram-se em mercadorias. Não há possibilidade de um desenvolvimento econômico e social sustentado que repouse em uma base de exploração depredadora do ambiente e dos seres que o constituem, bem como, no sistemático desperdício de bens e desrespeito pela natureza, tanto humana quanto não-humana.

As conseqüências de uma visão de futuro alicerçada no credo produtivista e na racionalidade instrumental, característica do paradigma científico e tecnológico da civilização industrial moderna, fazem-se sentir tanto na cultura e nas relações sociais, quanto nos efeitos causados nas condições de manutenção da vida do próprio planeta que "sinaliza um certo cansaço diante de vacas loucas, águas contaminadas, dejetos tóxicos, catástrofes nucleares, andróides gênicos, máquinas espirituais e próteses corpóreas siliconadas" (Carvalho, 2000:27).

O progresso dessa nova ordem mundial com seu corolário de desigualdade e destruição sistemática da natureza e dos laços de solidariedade inter-humana não é uma realidade inexorável. Ao contrário, as próprias virtualidades críticas contidas no conhecimento científico permitem, não só desvelar as potencialidades sombrias da realidade, como também entrever outras possibilidades. Diante de inúmeras alternativas futuras contidas no presente, impõe-se pensar estrategicamente em modos de viver sustentáveis.

O planejamento, como forma de conhecimento, por um lado, pode orientar-se por distintas racionalidades. Como planificação moderna seu fundamento está no mercado, na utilidade, no individualismo possessivo. Será, portanto, instrumento para gerir recursos escassos, técnica de controle social. Um planejamento emancipatório, por outro lado, assenta-se em bases relacionadas às novas formas de pensar do paradigma da complexidade (Morin, 1999).

O planejamento estratégico é aqui compreendido como ação coletiva que, em um contexto de incerteza (múltiplas possibilidades) busca, de acordo com a análise de situações específicas, caminhos para "modelar o comportamento humano e as relações sociais" ${ }^{\circ}$ em estruturas que assegurem a dignidade humana e a sustentabilidade social e natural, de modo a não comprometer as condições de vida das gerações futuras. O planejamento, assim definido, não será uma técnica social neutra e sim orientada ética e politicamente e exercida nos moldes de uma democracia radical.

O pensar estratégico remete a condições históricas específicas como, por exemplo, as condições de inserção do Brasil na nova ordem mundial e as potencialidades de uma planificação emancipatória como instrumento para projetar adequada articulação entre produção de conhecimento e sustentabilidade no Brasil. Reflexão que será esboçada a seguir.

\section{C\&T NO BRASIL: ESTRATÉGIAS PARA A SUSTENTABILIDADE}

O papel estratégico desempenhado pela ciência e tecnologia no contexto contemporâneo e a desigual difusão das capacitações para produzir e utilizar a ciência entre as diferentes nações recoloca, de forma ampliada, as dificuldades de inserção na economia mundial daqueles países periféricos e dependentes de conhecimento e inovação gerados nos centros dinâmicos da economia capitalista. Os países pertencentes a esse bloco são responsáveis por mais de $90 \%$ da produção científica mundial e sua população representa $20 \%$ da humanidade. Os restantes $80 \%$ da população mundial vivem em países que participam com menos de $10 \%$ da produção de C\&T (Hassam, 1999).

A incapacidade em produzir conhecimentos que possam ser incorporados como inovação ${ }^{6}$ afeta a entrada desses países nos mercados internacionais, impedindo sua participação com produtos novos ou mais competitivos. Sua competitividade passa, então, a depender de processos que comprometem as condições de vida de suas populações (baixos salários, desregulamentação do trabalho) ou que superexploram suas bases de recursos naturais.

A tendência à concentração da produção de conhecimento nos centros capitalistas do Norte (Estados Unidos, Europa e Japão, sobretudo) decorre de características históricas desses países no que se refere à geração endógena de ciência e tecnologia; à existência de sólidos vínculos entre unidades produtoras de C\&T, sociedade e Estado; bem como, à sua capacidade e disposição em atender às exigências crescentes de investimentos contínuos e de grande vulto.

Ao mesmo tempo, o exponencial aumento na intensidade das interações entre as coletividades científicas in- 
ternacionais, facilitado pelas novas tecnologias eletrônicas e de comunicação, tem levado à formação de redes em torno das atividades de C\&T. Tais redes ultrapassam os contextos institucionais de origem (universidades, institutos de pesquisa, empresas, governos) obtendo crescente autonomia (Castells, 2000).

A cooperação transnacional entre instituições de ensino e pesquisa e instituições corporativas vem assumindo grande importância, tornando-se norma nos centros desenvolvidos. Em contraste, a colaboração internacional é entorpecida nos países do sul em decorrência da baixa participação da indústria no financiamento da pesquisa (Braun, 1999).

\section{Impasses na Gestão de C\&T no Brasil: instituições e interesses}

Uma das questões-chave para análise da política científica e tecnológica no Brasil, da crise do setor e de sua configuração atual é a falta de vontade política para o planejamento estratégico em C\&T. Sendo a política um jogo de escolhas e constrangimentos, as respostas para as crises não são necessárias, e sim, representam escolhas das coalizões (que sustentam o Estado) dentro de um leque possível de alternativas (Baumgarten, 2001).

Algumas características históricas do processo de constituição da ciência e tecnologia no Brasil têm levado a opções (ações ou ausência de ações) por parte do Estado, que repercutem negativamente na infra-estrutura de pesquisa do país, enfraquecendo suas instituições, obstruindo suas potencialidades e dificultando a produção de conhecimento local.

A hegemonia dos interesses do empresariado internacionalizado, as dificuldades apresentadas pelas próprias deficiências da base técnica e sua relativa desvinculação com o desenvolvimento econômico - consideradas as condições históricas da acumulação capitalista no Brasil - contribuíram para a escolha preferencial de atuar com tecnologia importada. Essa situação levou as diferentes coalizões que assumiram o Estado a não priorizarem o estabelecimento de uma política científica e tecnológica, posto que o desenvolvimento do setor de C\&T não era visto como real necessidade.

A opção do empresariado (nacional e internacionalizado) de importar tecnologia agravou a distância entre demanda e oferta de conhecimentos locais, formando-se um círculo vicioso e cumulativo oposto ao processo de estimulação mútua prevalente nos países centrais, onde o processo coletivo de constituição da base técnica local conduz a uma crescente articulação entre setores produtivo e técnico-científico (Corrêa, 1998).

Todavia, a baixa incorporação de diferentes atores sociais, além dos cientistas na definição e controle da implementação das políticas do setor de $\mathrm{C} \& \mathrm{~T}$, conduziu a um modelo de desenvolvimento científico e tecnológico ${ }^{7}$ em que os recursos são definidos e alocados pelo Congresso Nacional (cujo interesse e participação no setor é restrito) e pelo presidente, com base no modelo econômico e nas forças políticas hegemônicas, enquanto a gestão da área - o estabelecimento de prioridades e a implementação das ações - é fortemente influenciada e dirigida pelos próprios cientistas, resultando em verbas decrescentes e respostas insuficientes relativamente a necessidades sociais (Baumgarten, 2001).

Entre os diversos impasses que dificultam o desenvolvimento científico e tecnológico brasileiro, destacam-se: a forma de financiamento da pesquisa executada nas universidades públicas; e a transposição de modelos de desenvolvimento técnico-científico dos grandes centros, ignorando necessidades próprias e limites impostos pelas condições locais para reproduzir adequadamente sistemas originários de outro contexto.

No primeiro caso, o financiamento com recursos externos aos orçamentos das universidades - por meio de agências de fomento - resultou em instabilidade causada pelas descontinuidades do financiamento ocasionadas por mudanças de orientação das agências ou outros problemas ligados a seu gerenciamento. Outrossim, como os centros universitários com melhores condições econômicas e culturais (infra-estrutura e massa crítica) obtêm mais facilmente recursos, consolidou-se um processo de seletividade como de regiões e de instituições, de equipes, de pesquisadores e de áreas prioritárias, o que provocou grande concentração das atividades de pesquisa na Região Sudeste.

No segundo caso obteve-se como resultado um baixo retorno dos esforços dirigidos para o desenvolvimento do setor tanto no que se refere à tecnologia/inovação,${ }^{8}$ quanto ao atendimento de necessidades sociais.

A escolha do setor produtivo em não financiar atividades de pesquisa e desenvolvimento (P\&D), importando tecnologias, traduziu-se em incapacidade da indústria brasileira em produzir inovação e impediu/retardou o desenvolvimento de mediações entre a pesquisa de corte acadêmico e a inovação, ou seja, aqueles produtos e processos que se destinam ao mercado. 
Esse tipo de conhecimento (inovação com base em $P \& D)$ nasce na indústria que deve estimular e aplicar recursos em P\&D. Em sua maioria, as inovações são incrementais e decorrem de pequenas mudanças. Sua base é científico-tecnológica, mas há muitas mediações para chegar à inovação. A falta de setores específicos de $\mathrm{P} \& \mathrm{D}$ nas empresas e a importação de tecnologias levou à incapacidade das empresas até para a construção de demandas para a universidade.

A tendência desse processo é reproduzir-se enquanto o empresariado mantiver a opção de não financiar ciência e tecnologia localmente. Os processos de privatização, fusões e incorporações, que aumentam a internacionalização do capital, tendem a agravar a situação, posto que as grandes empresas transnacionais mantêm suas estruturas de pesquisa e desenvolvimento nos países-sede, onde já há um ambiente (científico e cultural) propício para a inovação.

A década de 90 caracterizou-se por crescente verticalização da política de C\&T, ausência de planejamento global e baixa articulação entre os diferentes ministérios envolvidos, agências coordenadoras e financiadoras do desenvolvimento técnico-científico (Baumgarten, 2001). A debilidade das fontes tradicionais de recursos da União para atividades de pesquisa tornou-se o grande problema do período. Entretanto, de acordo com Guimarães (2001a), mesmo com baixo volume de investimentos e com uma política de C\&T inadequada em face das necessidades do país, o parque de pós-graduação e a produtividade dos pesquisadores aumentaram, o que pode ser explicado pelo sucesso do programa de qualificação de docentes e do grande número de doutores qualificados no período.

Em síntese, o Brasil do início do século XXI possui um parque científico/tecnológico caracterizado pela produção de corte acadêmico, com níveis razoáveis de produtividade, gerando pesquisas de boa qualidade. Ao mesmo tempo esse parque é bastante concentrado, pouco institucionalizado, apresenta atrofia tecnológica e problemas de financiamento - baixo volume de recursos e seletividade.

Duas ordens de problemas colocam-se, portanto, para avaliar a condução do setor: o primeiro conjunto de questões está relacionado à atrofia tecnológico/empresarial da pesquisa no país e decorre das características estruturais da economia brasileira e das opções de planejamento (ou falta de) orientadas por interesses desvinculados das necessidades sociais do Brasil.

Outra problemática articula-se, por um lado, à concentração de instituições, grupos e recursos em uma região ao lado do progressivo enfraquecimento de universidades e instituições localizadas fora dos grandes centros e que, entretanto, pela inserção em suas comunidades, teriam, talvez, melhores condições para encontrar respostas para problemas locais, desde que fossem adequadamente qualificadas em termos de infra-estrutura e pessoal docente e técnico.

Por outro lado, a conjunção de fatores como: redução significativa e continuada de investimentos no setor público (universidades e institutos); o inadequado volume de recursos destinado ao fomento da pesquisa; e, finalmente, o precário enraizamento na realidade nacional dos formuladores de políticas, bem como a falta de instrumentos de prospecção junto à sociedade - tem levado a iniciativas para o setor ${ }^{9}$ que tendem a imprimir maior seletividade, agravando os problemas existentes. Tais ações são, em geral, alicerçadas em forte miopia política e institucional que embaraça a visão sobre excelência acadêmica e impede a identificação das reais causas das carências tecnológicas, transferindo-as para a universidade, percebida como empecilho no rumo da inovação tecnológica.

Recentemente algumas mudanças vêm sendo feitas com a finalidade de encaminhar soluções para a questão tecnológica e a inserção do Brasil na nova ordem mundial. Entre essas adaptações estão: a criação dos fundos setoriais de pesquisa ${ }^{10}$ que, em princípio, devem cobrir as áreas estratégicas para o desenvolvimento nacional; e o Plano Plurianual 2000-2003 (PPA) que prevê o direcionamento de $80 \%$ dos recursos destinados a informação e conhecimento, para o desenvolvimento tecnológico e engenharias; $18 \%$ para o desenvolvimento científico e $1,6 \%$ para a difusão do conhecimento (Barros, 2001).

Se a idéia dos fundos é boa, suas formas de gestão vêm suscitando dúvidas e debates na coletividade científica e tecnológica, sobretudo quanto à criação do Centro de Gestão e Estudos Estratégicos. A proposta contida no PPA, por outro lado, resume a velha tática do cobertor curto, punindo a área científica em uma temática central como informação e conhecimento.

Uma nova proposta que merece destaque por não se pautar por uma lógica produtivista é o Programa de Apoio às Tecnologias Apropriadas, desenvolvido em parceria pelo CNPq e Estados da Federação. Destina-se a induzir, junto às instituições executoras locais e com base na identificação de problemas locais, projetos que possam trazer benefícios para essas populações e economias.

Em setembro de 2001 foi realizada a Conferência Nacional de Ciência, Tecnologia e Inovação proposta pelo gover- 
no federal como um meio para definir um projeto nacional de C\&T, capaz de estimular e fortalecer parcerias com os setores da sociedade, que teve como objetivo central o desenvolvimento social, econômico e cultural do país.

Os debates da Conferência tiveram como ponto de partida o Livro Verde (Silva e Melo, 2001), síntese da visão do governo no tema e documento base para encontros regionais. Uma breve análise desse documento ressalta os pressupostos envolvidos em sua elaboração: a aceitação, sem questionamentos, das novas formas de ordenação mundial - desregulamentação, flexibilização, atuação em redes - assumindo-as como princípios condutores para a reestruturação do setor de C\&T no Brasil, deixando de levar em conta diferenças de tipo e de nível de desenvolvimento entre economias centrais e periféricas.

A proposta de reforma no arcabouço institucional do sistema de C\&T, tanto no âmbito dos organismos executores, quanto no de fomento, desconsidera dois elementos importantes: o fato de que, concretamente, em sua maioria, o trabalho de pesquisa que se desenvolve no Brasil é realizado por grupos de pesquisa em instituições (Guimarães, 2001b); e as características e necessidades próprias do contexto de maior exclusão social.

A fixação, aparente no Livro Verde, em novos arranjos institucionais em forma de redes demonstra, não obstante, o desconhecimento do debate, que vem assumindo grande importância na Europa e mesmo nos Estados Unidos, sobre efeitos indesejáveis e riscos envolvidos nesse tipo de organização do trabalho científico, crescentemente relacionado a interesses econômicos e apresentando autonomia em relação a controles públicos governamentais ou não.

Outrossim, algumas falhas e ausências identificadas pela coletividade científica no Livro Verde, como: a falta de contextualização social; as deficiências de debate sobre compromisso social e participação da população no setor; a quase total ausência das ciências sociais; e as carências relativas à disseminação do conhecimento - bibliográfica e digital; entre outras, podem ser vistas como indicadores da forte presença, no texto, de uma abordagem tecnocrática e produtivista.

A aceitação passiva e a incorporação, sem críticas, da nova morfologia social composta por fluxos financeiros globais, teias de relações políticas e institucionais, redes midiáticas e orientada pelo espírito do cálculo racional e pela mercadorização do conhecimento, não parece o melhor ponto de partida para construir um desenvolvimento econômico e social sustentável.

\section{CONCLUSÃO}

A crítica da racionalidade instrumental própria do paradigma da ciência moderna permite visualizar um novo sentido de tempo, para além do encadeamento mecânico envolvido no desdobramento causal dos acontecimentos normais. Um tempo heterogêneo, pontuado por momentos propícios e oportunidades a serem capturadas (Löwy e Bensaïd, 2000).

Perceber a história como processo aberto, pleno de possibilidades, permite a ruptura como o sentido de tempo linear a atual noção de progresso. Faculta, também, pensar o futuro como aposta racional. Essa aposta pode ser em uma outra globalização: "a mundialização de alternativas emancipatórias de relações sociais, econômicas e de gestão pública" (Tavares dos Santos, 2001:165).

A aposta na possibilidade de um desenvolvimento sustentável no Brasil tem como fundamento uma nova concepção de ciência na qual os princípios da solidariedade e da dignidade humana substituem os princípios do produtivismo e do cálculo racional.

Algumas condições parecem imprescindíveis para que um país como o Brasil possa construir um desenvolvimento baseado na sustentabilidade humana, solidária com a biosfera e com as gerações futuras. Entre elas é possível apontar:

- fortalecimento da capacidade científica nacional e de sua reflexividade mediante consolidação de sua base de pesquisa - grupos e instituições: universidades institutos de pesquisa, escolas (Viotti, 2001; Bartholo Jr. e Bursztyn, 2001; Guimarães, 2001b);

- valorização das ciências sociais no desenvolvimento de tecnologias da sustentabilidade, tomando-as como técnicas sociais que promovem a interação entre ciência e tomada de decisões;

- valorização dos conhecimentos locais e identificação de necessidades em nível nacional, regional e de prioridades no contexto internacional, por meio de avaliações prospectivas com base em conhecimento científico;

- implantação de bases de dados nacionais e sistemas de informação em C\&T acessíveis a todos. Utilização das informações para a formulação de políticas. Construção de instrumentos de avaliação das políticas e do fomento (Viotti, 2001; Bartholo Jr. e Bursztyn, 2001; Guimarães, 2001b);

- criação de instrumentos capazes de melhorar a comunicação, cooperação e disseminação de informações inter- 
namente às coletividades científicas e tecnológicas e entre elas e os centros de decisão política. Divulgação de ciência e tecnologia entre o público em geral e com estudantes visando ampliar a capacidade do senso comum para melhorar as possibilidades de democratizar decisões (Bartholo Jr. e Bursztyn, 2001);

- no que se refere à tecnologia, empreendimento de esforços para melhorar a capacidade brasileira para absorver e aperfeiçoar tecnologias. A inovação deve ser buscada em paralelo ao esforço de generalização da estratégia de aprendizado ativo (Viotti, 2001);

- estímulos à realização de esforço tecnológico diretamente por parte das empresas e em cooperação com elas e requerimento de contrapartidas efetivas a esses estímulos (Viotti, 2001);

- integração e compatibilização com políticas de C\&T e políticas econômicas e educacionais, bem como as ações entre níveis federal, estadual e municipal; encaminhar a questão das desigualdades regionais e das potencialidades e capacidades dos sistemas locais de conhecimento, buscando qualificá-los tendo em vista sua proximidade e maior identificação com as necessidades locais.

O Fórum Social Mundial em Porto Alegre - espaço privilegiado de modelagem de alternativas à globalização hegemônica (Santos, 2000) - com sua infinidade de temas, necessidades, identidades, interesses e vontades parece um bom exemplo da possibilidade de projetar, com base em novo sentido de tempo, utopias que superem as conquistas da modernidade, incorporem o domínio coletivo e consciente das ciências, das técnicas, das escolhas de produção, de distribuição e de consumo de bens materiais e não-materiais. Sonhar utopias, entretanto, não é suficiente. É necessário buscar os meios de concretizálas, impõe-se, pois, pensar estrategicamente, planejar novos modos de conhecimento que sirvam como alavancas de uma sociedade sustentável.

\section{NOTAS}

1. Para detalhes acerca da constituição da ciência moderna e as controvérsias envolvidas ver, entre outros, Rossi (1992); Henry (1998); Santos (2000).

2. O esboço de paradigma da planificação moderna, aqui apresentado, foi elaborado com base em leituras e debates realizados na minha participação como professora convidada em um seminário sobre o tema organizado pelo Prof. José Vicente Tavares dos Santos no Programa de Pós-Graduação em Sociologia/UFRGS. Os conceitos de paradigma da planificação moderna e planificação emancipatória encontram-se desenvolvidos no artigo "Novas questões sociais mundiais, projetos sociais e culturais e a planificação emancipatória" de autoria do Prof. José Vicente Tavares dos Santos.

3. Considerando os aspectos mais genéricos das práticas de Welfare State, pode-se afirmar que esse se constitui, em essência, em um padrão mínimo de renda, alimentação, saúde, habitação e instrução assegurado, pelo Estado, a qualquer cidadão, como um direito político.

4. Na literatura de ficção científica, bem como no cinema, há inúmeros exemplos de antecipações em torno dos temas aqui tratados, entre eles pode-se citar: $O$ admirável mundo novo de Aldous Huxley, 1984 de George Orwel e, mais recentemente, os filmes Blade Runner, de Ridley Scott, Matrix e Gattaca, a experiência genética.

5. A idéia, aqui, é que se pode retomar o conceito de Mannheim (1974) sobre técnicas sociais - vistas como aquelas práticas e operações cujo objetivo é modelar o comportamento humano e as relações sociais em uma perspectiva de planejamento diferente da planificação moderna. Tal visão estaria implícita no conceito de utopia do autor.

6. Apenas $2 \%$ das inovações tecnológicas são produzidas pelos países do Sul e 0,02\% na América Latina (Nunes e Ferreira, 1999).

7. O MCT não possui orçamento próprio e os recursos (e políticas) para o setor de C\&T encontram-se dispersos em diversos ministérios, entre os quais o Ministério da Educação que trata das questões relativas ao ensino superior e o Ministério da Administração que trata das questões referentes ao funcionalismo público.

8. De acordo com Guimarães (2001a) há evidências que durante os anos 90, no Brasil, a quantidade e qualificação do pessoal envolvido em pesquisa e desenvolvimento (P\&D) nas empresas diminuiu.

9. Tais como o Programa de Apoio a Núcleos de Excelência, Institutos do Milênio, entre outros.

10. Os fundos são formados mediante recursos provenientes de royalties a serem pagos por empresas que explorem setores estratégicos: petróleo e gás, atividades espaciais, energia elétrica, recursos minerais, recursos hídricos, informática, saúde, agronegócios, biotecnologia, aeronáutica. Foram também criados o Fundo de Infra-estrutura de Pesquisa e o Fundo Verde-Amarelo que destinam-se, respectivamente, ao financiamento de projetos de recuperação da infra-estrutura das universidades e de institutos de pesquisa e ao financiamento de projetos de integração universidade/empresa.

\section{REFERÊNCIAS BIBLIOGRÁFICAS}

ALBAGLI, S. "Novos espaços de regulação na era da informação e do conhecimento". In: LASTRES, H. e ALBAGLI, S. (orgs.). Informação e globalização na era do conhecimento. Rio de Janeiro, Campus, 1999, p.290-313.

ARAÚJO, H. (org.). Tecnociência e cultura (Apresentação). São Paulo, Estação Liberdade, 1998.

ARRIGHI, G. O longo século XX: dinheiro, poder e as origens de nosso tempo. São Paulo, UNESP/Contraponto, 1996.

BARROS, F.A. "Os avanços da tecnociência, seus efeitos na sociedade contemporânea e repercussões no contexto brasileiro". In: BAUMGARTEN, M. (org.). A era do conhecimento: Matrix ou Ágora? Porto Alegre, UNB/UFRGS, 2001, p.73-87.

BARTHOLO JR., R. e BURSZTYN, M. "Prudência e utopismo: ciência e educação para a sustentabilidade”. In: BURSZTYN, M. (org.) Ciência, ética e sustentabilidade. São Paulo, Cortes; Brasília, Unesco, 2001, p.159-88.

BAUMGARTEN, M. "Globalização e ciência \& tecnologia no limiar do século XXI: os anos 90 no Brasil”. In: BAUMGARTEN, M. (org.). A era do conhecimento: Matrix ou Ágora? Porto Alegre, UNB, UFRGS, 2001, p.89-119. 
BETTELHEIM, C. Planificação e crescimento acelerado. Rio de Janeiro, Zahar, 1968.

BRAUN, T. et. alii. As grandes tendências da ciência mundial. Unesco, El Correo, maio 1999.

CARVAlHO, E. "Tecnociência e complexidade da vida". São Paulo em Perspectiva. São Paulo, Fundação Seade, v.14, n.3, jul.-set. 2000, p.26-31.

CASTElls, M. A sociedade em rede. $3^{\text {a }}$ ed. São Paulo, Paz e Terra, 2000.

CORREAA, M. Politicas de C\&T no Brasil dos anos 90: o mito da excelência. Porto Alegre, PPGS/UFRGS, mimeo, 1998.

GUIMARÃES, R. "Entrevista para Jornal da Universidade". Jornal da UFRGS. Porto Alegre, 08/05/2001a.

. "Livro Verde e as novas instituições". Jornal da Ciência. Rio de Janeiro, n.465, 31/08/2001b.

HABERMAS, J. Técnica e ciência como ideologia. São Paulo, Abril, 1975. (Coleção Os Pensadores, v. XLVIII).

HASSAM, M. "Disparidades Norte-Sul na produção e uso do conhecimento". Jornal da Ciência. Rio de Janeiro, n.408, 19/03/1999.

HENRY, J. A revolução científica. Rio de Janeiro, Zahar, 1998.

HOBSBAWM, E. A era dos extremos. Rio de Janeiro, Paz e Terra, 1996.

JAMESON, F. "Cinco teses sobre o marxismo atualmente existente". In: WOOD, E. e FOSTER, J. Em defesa da história: marxismo e pós-modernismo. Rio de Janeiro, Zahar, 1999, p.187-95.

LASTRES, H. e ALBAGLI, S. (orgs.). Informação e globalização na era do conhecimento. Rio de Janeiro, Campus, 1999.

LÖWY, M. "De Marx ao ecossocialismo". In: LÖWY, M. e BENSAÏD, D. Marxismo, modernidade e utopia. São Paulo, Xamã, 2000, p. 227-38.

LÖWY, M. e BENSAÏD, D. Marxismo, modernidade e utopia. São Paulo, Xamã, 2000.

MANNHEIM, K. Sociologia da cultura. São Paulo, Perspectiva/Edusp, 1974.

MARINHO, D. e QUIRINO, T. "Considerações sobre o estudo do futuro”. Sociedade e Estado. Brasília, v.X, n.1, jan.-jul. 1995, p.13-48.
MORAES, A. Meio ambiente e ciências humanas. $2^{\mathrm{a}}$ ed. São Paulo, Hucitec, 1997.

MORIN, E. O método 3. O conhecimento do conhecimento. Porto Alegre, Sulina, 1999 (ed. original, 1986).

NUNES, R. e FERREIRA, R. "Inovações tecnológicas na América Latina". Jornal da Ciência. Rio de Janeiro, n.425, 19/11/1999.

ROIO, M. del. "O Estado da globalização". Estudos de sociologia. Araraquara, ano 3, n.6, 1999, p.143-48.

ROSSI, P. A ciência e a filosofia dos modernos. São Paulo, Unesp, 1992.

SANTOS, B. Introdução a uma ciência pós-moderna. Rio de Janeiro, Graal, 1989.

. A crítica da razão indolente: contra o desperdício da experiência. São Paulo, Cortez, 2000.

SILVA, C. e MELO, L. (orgs.). Livro verde - Ciência, tecnologia e inovação: desafios para a sociedade brasileira. Brasília, MCT/ Academia Brasileira de Ciências, 2001.

TAVARES DOS SANTOS, J. "Novas questões sociais mundiais, projetos sociais e culturais e planificação emancipatória". Humanas. Porto Alegre, IFCH, v.24, n.1/2, 2001, p.163-85.

VICO, G. [1710] On the most ancient wisdom of the italian. Ithaca, 1988.

VILAS, C. "Seis idéias falsas sobre a globalização". Estudos de sociologia. Araraquara, ano 3, n.6, 1999, p.21-62.

VIOTTI, E. "Ciência e tecnologia para o desenvolvimento sustentado brasileiro". In: BURSZTYN, M. (org.). Ciência, ética e sustentabilidade. São Paulo, Cortês; Brasília, Unesco, 2001, p.143-58.

WOOD, E. e FOSTER, J. Em defesa da história: marxismo e pós-modernismo. Rio de Janeiro: Zahar, 1999.

ZAMORA, F. La sociedad económica moderna: capitalismo, planeación y desarrollo. México, FCE, 1966.

Maíra Baumgarten: Professora do Departamento de Educação e Ciências do Comportamento da FURG/RS (mayrab@terra.com.br). 